\title{
Astrocytes: Integrative Regulators of Neuroinflammation in Stroke and Other Neurological Diseases
}

\author{
Egle Cekanaviciute $^{1}$ • Marion S. Buckwalter ${ }^{1,2,3}$
}

Published online: 27 September 2016

(C) The American Society for Experimental NeuroTherapeutics, Inc. 2016

\begin{abstract}
Astrocytes regulate neuroinflammatory responses after stroke and in other neurological diseases. Although not all astrocytic responses reduce inflammation, their predominant function is to protect the brain by driving the system back to homeostasis after injury. They receive multidimensional signals within the central nervous system and between the brain and the systemic circulation. Processing this information allows astrocytes to regulate synapse formation and maintenance, cerebral blood flow, and blood-brain barrier integrity. Similarly, in response to stroke and other central nervous system disorders, astrocytes detect and integrate signals of neuronal damage and inflammation to regulate the neuroinflammatory response. Two direct regulatory mechanisms in the astrocyte arsenal are the ability to form both physical and molecular barriers that seal the injury site and localize the neuroinflammatory response. Astrocytes also indirectly regulate the inflammatory response by affecting neuronal health during the acute injury and axonal regrowth. This ability to regulate the location and degree of neuroinflammation after injury, combined with the long time course of neuroinflammation, makes astrocytic signaling pathways promising targets for therapies.
\end{abstract}

Keywords Astrocyte - Neuroinflammation - Glial scar . Stroke $\cdot$ Brain injury

Marion S. Buckwalter

marion.buckwalter@stanford.edu

1 Department of Neurology and Neurological Sciences, Stanford Medical School, Stanford, CA 94305, USA

2 Department of Neurosurgery, Stanford Medical School, Stanford, CA 94305, USA

3 Stanford Stroke Center, Stanford Medical School, Stanford, CA 94305, USA

\section{Astrocytic Functions in the Healthy Central Nervous System}

Astrocytes play 2 major roles in the resting central nervous system (CNS): they integrate signals and maintain homeostasis between its nervous, immune, and vascular components. Several excellent reviews exist on the biology of astrocytes [1-4]. Briefly, their morphology and location within the brain is ideal for their integrative role. Astrocytic processes contact each synapse and astrocytic endfeet make up the internal layer of the blood-brain barrier (BBB), which allows them to react to local changes in neuronal activity, as well as respond to systemic perturbations in the rest of the body. They provide trophic and functional support to neurons by transporting glucose, neurotrophic factors, and neurotransmitters such as glutamate. In addition, astrocytes keep the immune system quiescent at baseline by regulating the permeability of the BBB and microglial activation states.

There is significant astrocyte heterogeneity in morphology and function. Although astrocyte heterogeneity studies have been slowed down by lack of pan-astrocyte surface markers [5], we are beginning to understand how and why astrocytes vary, and to develop new tools to study them. Studies using human glial fibrillary acidic protein (GFAP)-enhanced green fluorescent protein mice show that brain region determines astrocyte morphology, density, and proliferation level [6], as well as gene expression [7]. Even within the same brain regions (olfactory bulb, spinal cord), astrocytes in different layers can manifest different morphological characteristics $[8,9]$ and develop in response to different factors [10]. Cortical astrocytes are divided into 2 main morphological subtypes: protoplasmic astrocytes, which are located in the gray matter, and fibrous astrocytes, which are found in the white matter [3]. Resting protoplasmic cortical astrocytes have a globoid morphology and occupy distinct, nonoverlapping 
domains, which coordinate the formation and functions of synapses $[3,11]$.

Astrocytes play major roles in neuronal function. They coordinate formation and function of synapses during development [11-13] and provide baseline trophic support to neurons by accumulating intracellular energy reserves in the form of glycogen granules that they can convert to lactate to supply to neurons [14]. Glutamate transporter expression by astrocytes functions to remove the neurotransmitter glutamate from the synaptic cleft, and is not uniform, varying according to developmental stage (more early than late) and brain region (most in radial glia) [15]. Importantly, the same trophic functions astrocytes have in an uninjured brain can be employed to reduce neuronal injury in disease, including stroke.

Higher-order functional diversity is also conferred by differences in astrocytic connections. Astrocytes occupy distinct, nonoverlapping domains in resting CNS [11] and can be coupled to each other via gap junctions (reviewed in [16]). They can be more strongly coupled within brain regions that function together. For example, within the whisker barrel cortex astrocytes are more coupled within barrels that control the same whisker than between barrels that control different whiskers [17]. Astrocytes are also coupled to oligodendrocytes [18] and support them via lactate transfer [19].

Finally, astrocytes are able to coordinate immune responses in the healthy brain at key points during its development by regulating microglial activation [13] and BBB induction [20]. The same immunoregulatory and neuroprotective mechanisms that allow astrocytes to maintain homeostasis in the healthy brain are utilized in astrocytic responses to injury, including stroke.

\section{Stroke and Astrocytes}

Stroke kills $12 \%$ of all people worldwide, making it the second most common cause of mortality (http://www.who. int/mediacentre/factsheets/fs310/en/). Neuroinflammation peaks during the first week after stroke, known as the subacute period [21]. There is a growing body of evidence that astrocytes are important in situ regulators of the neuroinflammatory response to stroke. Astrocytes become reactive in the subacute time frame of 2 days to 1 week after stroke and form a scar around stroke core by 2 weeks [22].

The majority of our knowledge of reactive astrocyte functions in neuroinflammatory responses stems from research using disease models other than stroke. For example, spinal cord injury (SCI), traumatic brain injury (TBI), and brain infection models have all been used to understand what role astrocytes play in influencing the location, duration, and physical extent of neuroinflammation in the brain. In the following sections of this review we give examples of all of these models, as well as stroke. Although many of these astrocytic roles may be the same across neuroinflammatory states, some are known to be different, and the current state of knowledge is only beginning to uncover the complexity of astrocytic responses. Therefore, we highlight studies of astrocyte functions in stroke and emphasize differences in astrocytic roles in distinct neuroinflammatory states when information is available.

\section{Reactive Astrocytes in Central Nervous System Disease}

During central nervous system (CNS) injury astrocytes sense molecular changes in their extracellular environment and in cells to which they are coupled, and alter their morphological and functional characteristics to adopt a "reactive" phenotype. The history of how the term "reactive" developed is nicely summarized elsewhere [23]; the first mention of astrocyte changes in disease was in 1895 and strong GFAP expression became the hallmark of reactive astrocytes in the 1970s. In addition to upregulation of GFAP, reactive astrocytes alter their morphology and gene expression.

As would be expected by their locations throughout the brain and their functions in the normal brain, astrocytes become reactive when they sense injury. In stroke, this includes oxygen and glucose deprivation, and in most neurological injuries and diseases the release of neurotransmitters, as well as adenosine triphosphate (ATP) from damaged neurons [24-26]. During infection astrocytes can be invaded by intracellular pathogens or activated by lipopolysaccharide and other ligands of innate immunity that bind to Toll-like receptors (reviewed in [27, 28]). Furthermore, immune cells that invade the site of injury or infection release a variety of cytokines that further stimulate astrocyte activation (Tables 1 and 2).

Differences in the strength of these signals leads to a spectrum of astrocyte "reactivity". In general, the most activated and morphologically distinct astrocytes are observed adjacent to the injured region, with less activated astrocytes farther away in the remaining healthier tissue [34, 37, 47]. Reactive astrocytes proliferate, become hypertrophied, upregulate the expression of intermediate filament proteins, cytokines and chemokines, and cluster into polarized bundles around the injured region. The polarized astrocytes combine with extracellular matrix (ECM) components to form a scar, which walls off the injured region from neighboring healthier tissue.

Astrocyte activation typically occurs during the time period that coincides with peak inflammatory response. In CNS injuries such as stroke, TBI, and SCI, the initial tissue destruction that is caused by ischemia or physical trauma is followed by a subacute period that lasts up to a week, during which the tissue can be further damaged by inflammation $[69,78]$. This subacute period coincides with astrocyte activation and their expression of cytokines; however, changes in astrocyte morphology and astroglial scars can persist chronically [79]. By 


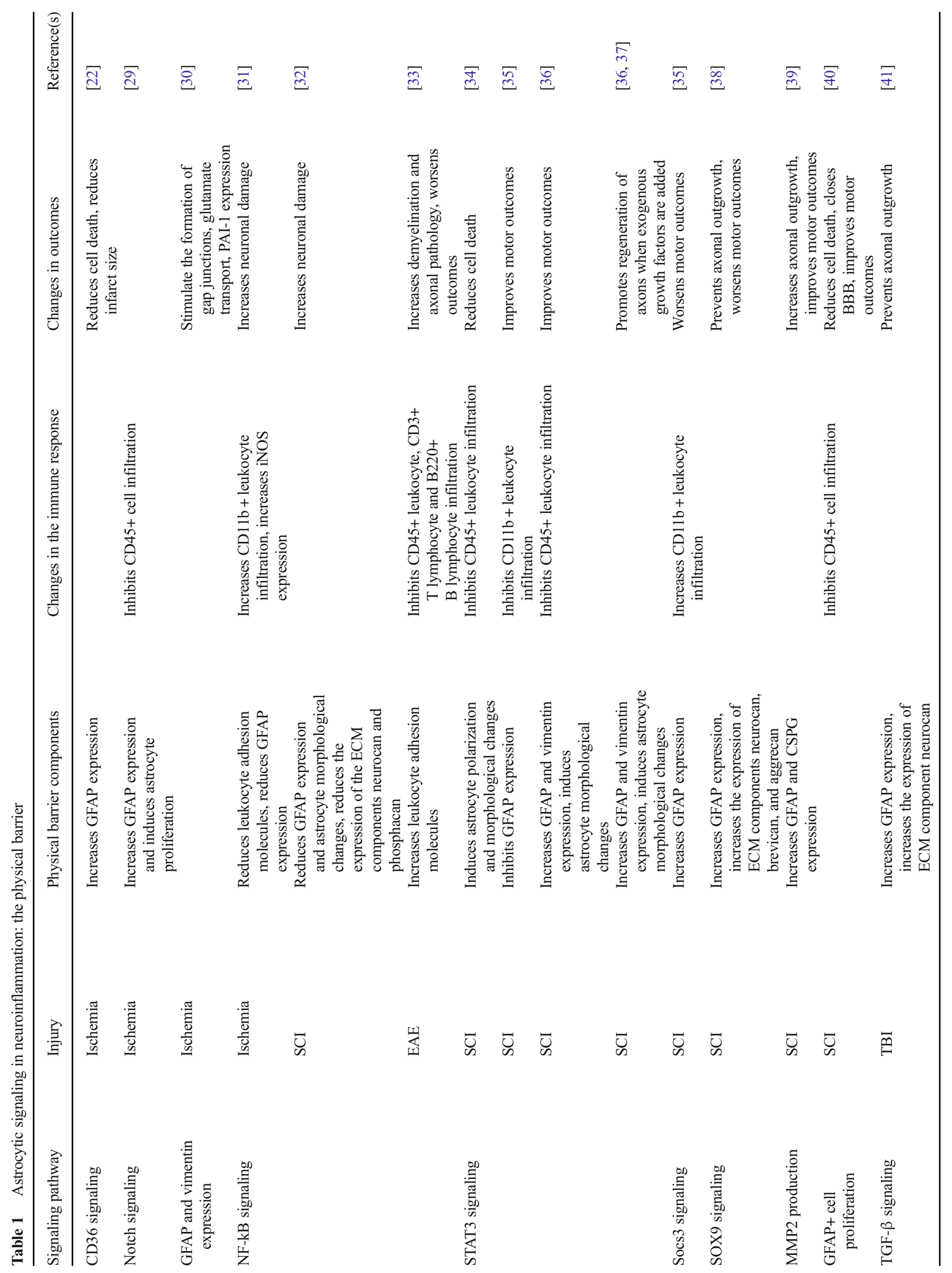




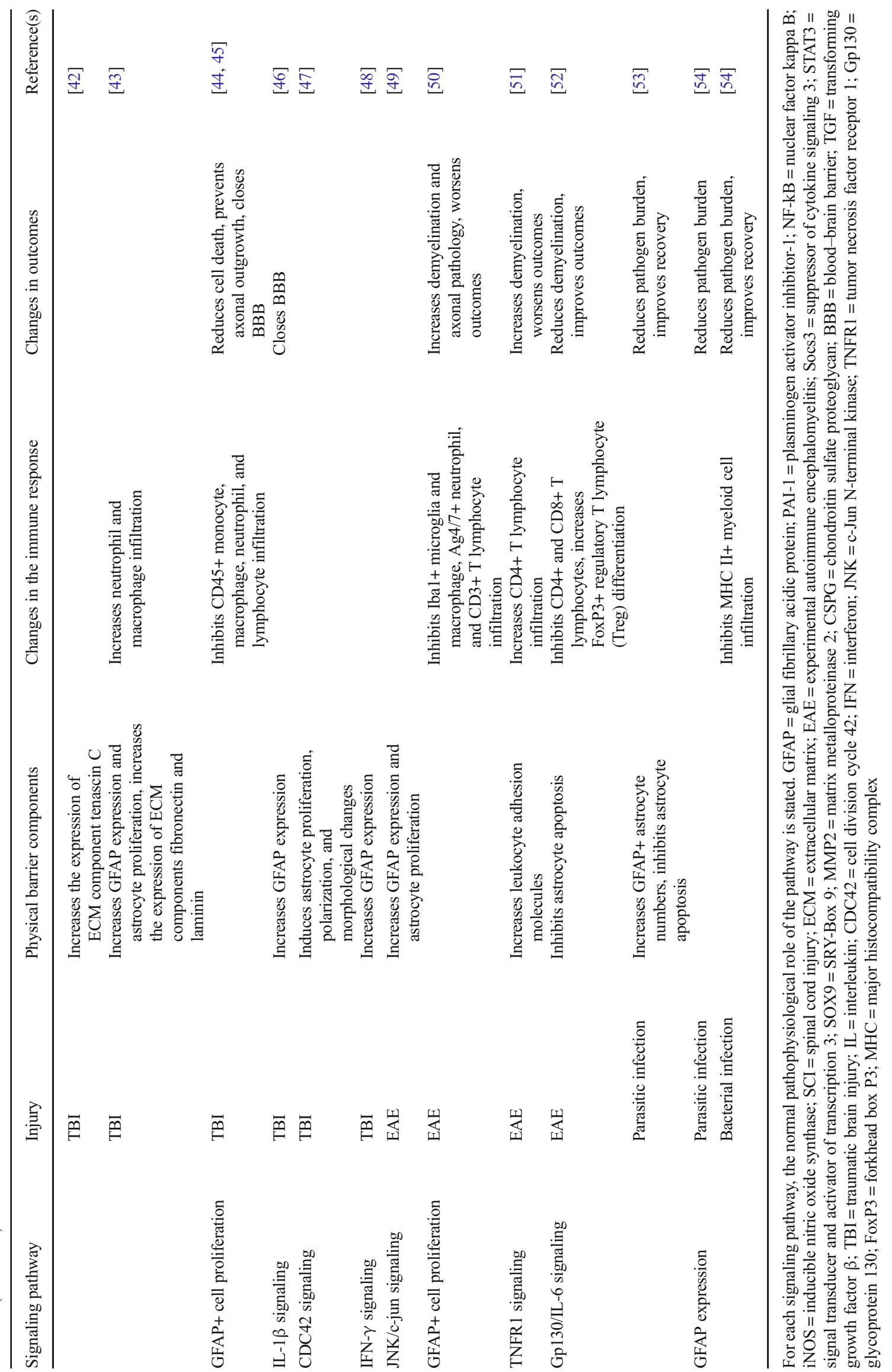




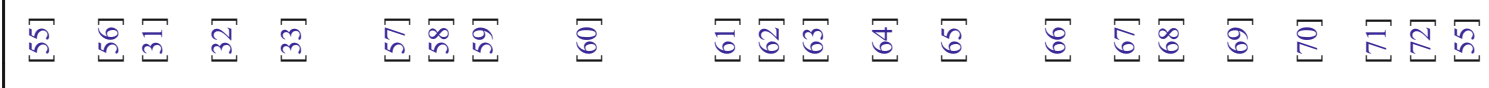

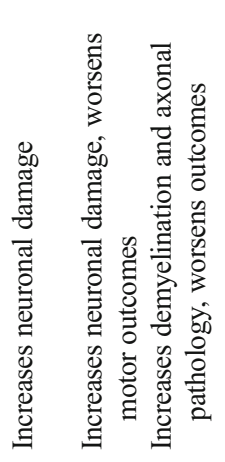

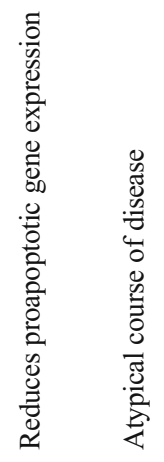

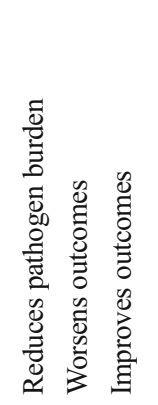

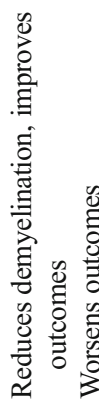

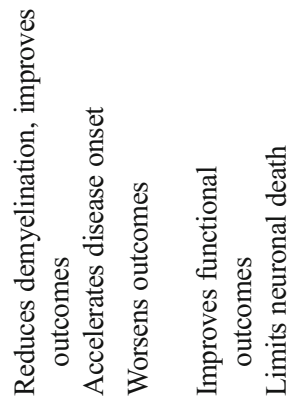

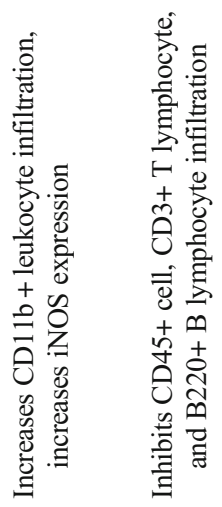

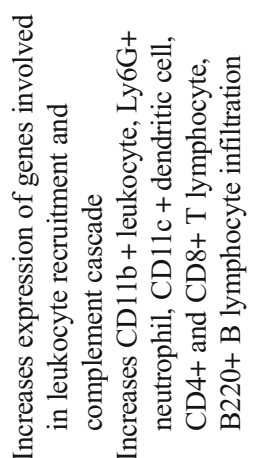

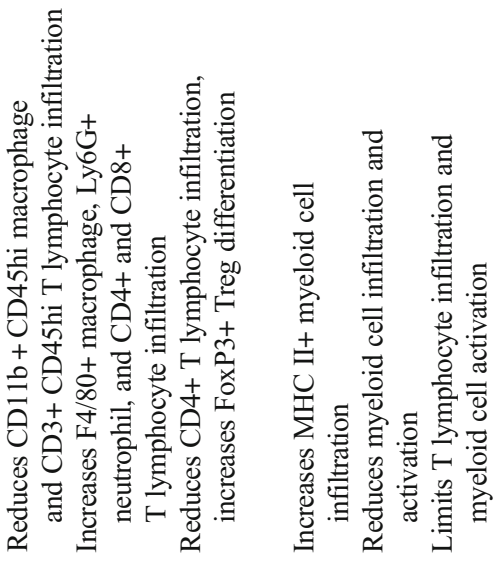

$0 \quad$ i

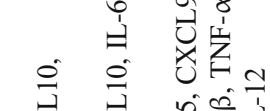

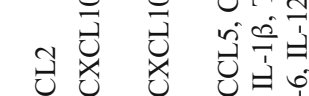

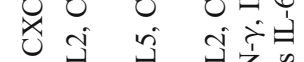

式

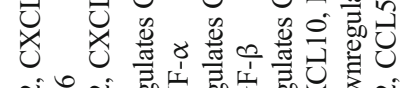

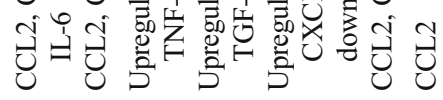

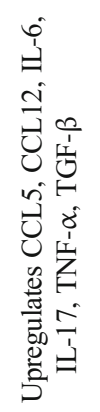

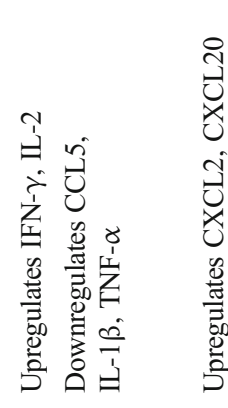

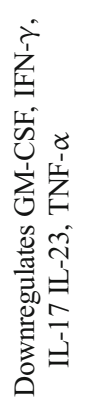

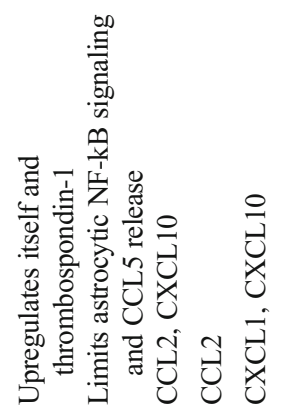

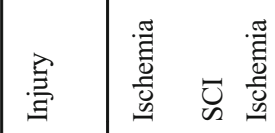

$\overrightarrow{0}$

$$
\text { (n) }
$$
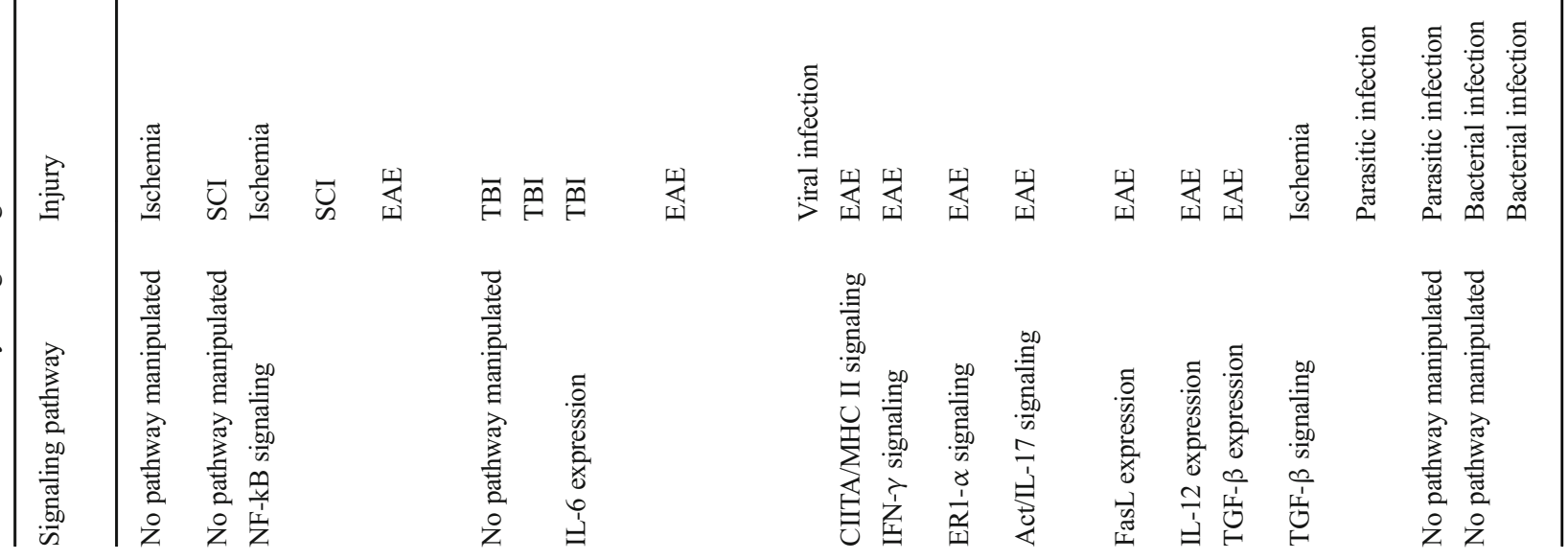


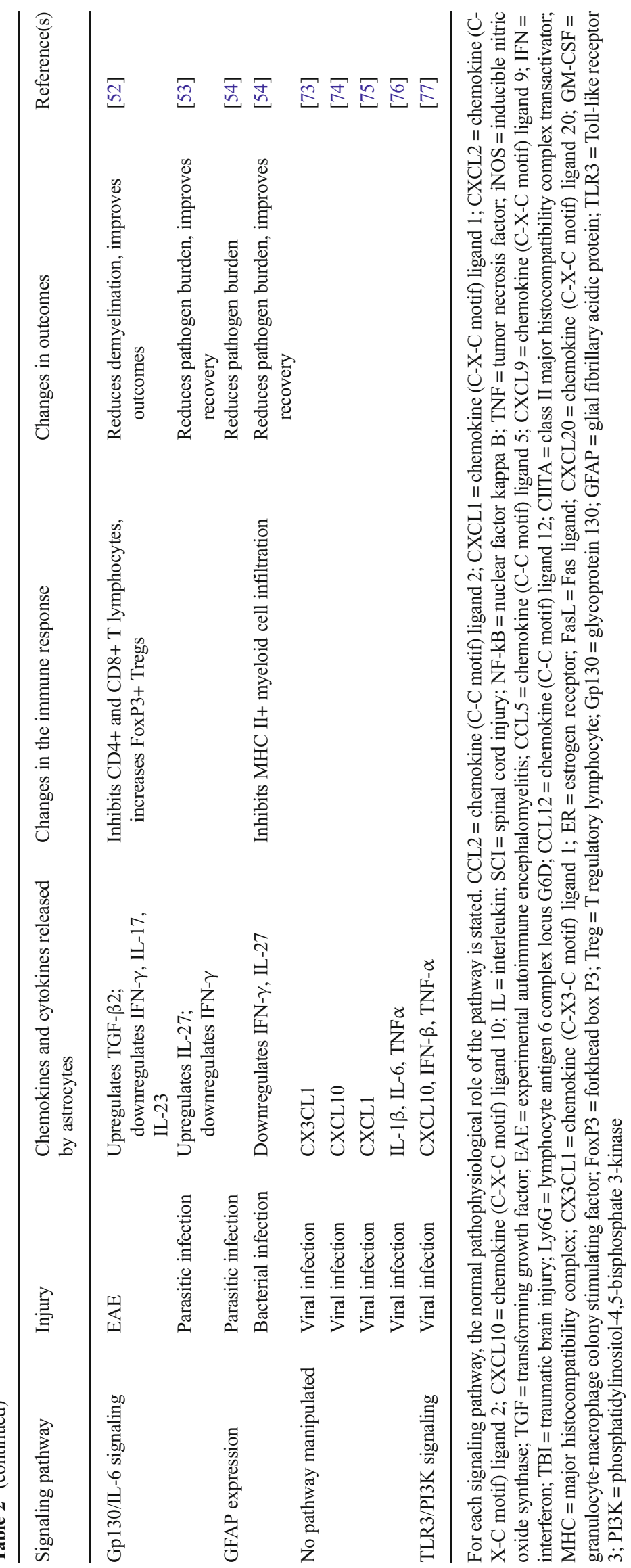


comparison, the acute phase of bacterial, viral, and parasitic infections is defined as the initial pathogen invasion of the CNS, which can take hours to weeks, depending on the pathogen and the route of infection $[28,54,70,80]$. Astrocytes are strongly activated during this acute phase of infection as well as at the first peak of immune infiltration in models of autoimmune encephalomyelitis [50].

Regardless of the cause of CNS injury, the response of reactive astrocytes can be summarized by 2 general mechanisms that share the purpose of limiting inflammation. Conceptually, these 2 mechanisms produce a double barrier. The first, "physical", barrier is the astrocytic scar, which is formed by polarized bundles of reactive astrocytes together with ECM components and physically surrounds the injured region [34]. Although there is some evidence that ECM components can directly activate immune cells after injury [81], the primary role of the ECM remains structural; therefore, for the purpose of this review it will be classified as part of the physical barrier. The second, "molecular", barrier is composed of the signaling molecules that are produced and secreted by astrocytes to regulate the infiltration and activation of immune cells. These molecules, which include chemokines and cytokines, are not fixed to a specific physical location but instead diffuse away from reactive astrocytes, creating signaling gradients throughout the injured tissue. Finally, reactive astrocytes may indirectly modulate inflammation by altering neuronal responses to ongoing metabolic and toxic injuries.

\section{Reactive Astrocytes Form a Physical Barrier}

The physical barrier formed by astrocytes has primarily been studied not only in the context of traumatic brain and spinal cord injuries but also occurs after stroke [22, 34]. It primarily serves to wall off and limit inflammation to the injured region (Table 1). It is formed by proliferating astrocytes that upregulate intermediate filament proteins, including GFAP and vimentin [82]. In addition, astrocytes adjacent to the injury site change their morphology to become hypertrophied, elongated, and polarized. During polarization, elongated astrocytes aggregate into bundles that are clustered first orthogonal, and then parallel to the injury site. These astrocyte bundles surround the injured tissue and invading immune cells [34, 47]. Although the astrocytes farther away from the injury site also become hypertrophied, they do not form bundles, and retain their original nonoverlapping domains instead [83, 84].

Reactive astrocytes further strengthen the physical barrier to inflammation by augmenting intercellular connections and by producing ECM components. After injury, reactive astrocytes upregulate connexin family proteins, which form gap junctions and thus augment intercellular connections [85]. In addition, reactive astrocytes upregulate the expression of
ECM proteins fibronectin, laminin, and tenascin [41-43]. as well as chondroitin sulfate proteoglycans (CSPGs), including neurocan, CSPG4 (also known as nerve/glial antigen-2) and CSPG6 [39, 41, 43, 86-88]. These ECM components combine with polarized astrocytes to form a tight barrier that physically impedes immune cells from escaping the injury site. During infection, a similar physical barrier is formed by $\mathrm{GFAP}^{+}$hypertrophied astrocytes and ECM components. This barrier surrounds the infectious foci that contain pathogens, damaged neurons, and invading immune cells [76, 89-91].

The reactive astrocyte barrier is crucial for localizing immune cells and, when present, infectious pathogens in the injured region. For example, ablating proliferating $\mathrm{GFAP}^{+}$ cells exacerbates immune cell infiltration in rodent models of TBI and experimental autoimmune encephalomyelitis $[44,50]$. Similarly, knocking out GFAP increases the pathogen burden during a bacterial infection with Staphylococcus aureus or a parasitic infection with Toxoplasma gondii [54]. In contrast, knockout of GFAP by itself does not affect stroke size [30]. Since GFAP is a structural protein, these results likely represent the functions of the physical, rather than molecular, barrier formed by astrocytes.

Although the physical barrier formed by astrocytes is essential to limit tissue damage during peak inflammation, its role in the late postinjury period has not been as clear. There is some evidence that it can become disadvantageous later after injury by preventing axonal outgrowth and behavioral recovery. In particular, CSPGs that are produced in the scar have been shown to impede axonal outgrowth [92-94]. Similarly, although astrocyte proliferation and upregulation of ECM components limit cell loss early after TBI, they are also associated with less axonal outgrowth and worse motor outcomes later in the recovery period [39]. However, recent groundbreaking work in SCI has demonstrated that exogenous growth factor application can improve axonal outgrowth more effectively in the presence of a normal scar than in animals with impaired astroglial scar formation [37].

\section{Reactive Astrocytes Secrete a Molecular Barrier}

In addition to forming a scar around the injury site, reactive astrocytes can regulate the immune response by secreting chemokines and cytokines that diffuse throughout the injury site and surrounding regions. This molecular barrier to inflammation mediates immune cell infiltration and function in injuries that evoke both innate and adaptive immune responses. Intracellular signaling pathways of chemokines and cytokines in astrocytes, as in other immune cells, interact in networks that contain both pro- and anti-inflammatory components (Tables 2 and 3). 


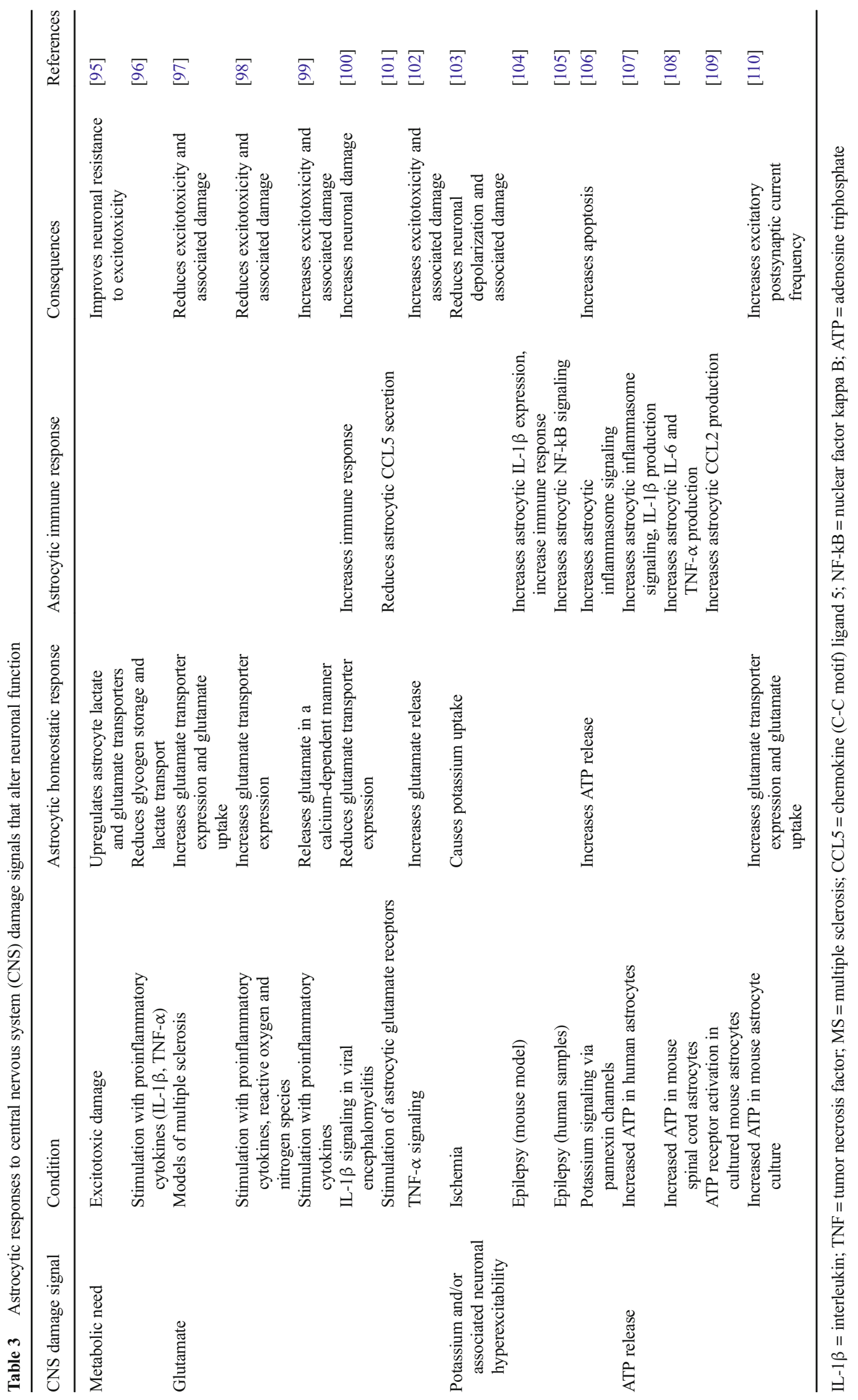


The innate immune response is immediate, stereotyped, and forms the first line of defense against injury. In stroke, it typically peaks between $12 \mathrm{~h}$ and 3 days after the injury occurs [111]. The innate response has both humoral and cellular components. The humoral component of the innate immune response includes the complement system and blood coagulation cascades, while its cellular component consists of basophils, eosinophils, mast cells, natural killer cells, and myeloid cells. Activated myeloid cells perform phagocytosis, which is essential to clear pathogens and dead cell debris from the injury site (reviewed in [112]). Acute injury or infection in the CNS attracts and activates both peripheral myeloid cells, such as macrophages and neutrophils, and CNS-resident myeloid cells - microglia.

By contrast, the adaptive immune response develops over a longer time scale, typically peaking between 1 and 3 weeks, depending on the injury or pathogen $[69,113]$. Adaptive immunity is activated and stimulated by components of the innate immune response, and has been well reviewed elsewhere [114-118]. The adaptive immune response is initiated by antigen presentation using major histocompatibility complex (MHC) II molecules, which are expressed on proinflammatory myeloid cells. The effector cells of the adaptive immune response are $\mathrm{T}$ and $\mathrm{B}$ lymphocytes, which invade the inflamed CNS from the periphery and destroy pathogens both by direct cytotoxicity and by antibody-mediated responses. Reactive astrocytes can regulate the adaptive immune response by releasing cytokines and chemokines, some of which are also used to mediate the innate immune response [119].

Astrocytes are commonly considered part of the cellular component of the innate immune response. Indeed, astrocytes act as key but not sole controlling members of the networked immune response to injury. While they instruct microglia, peripheral macrophages, and other immune cells they, in turn, also receive reciprocal signals from those cells. However, unlike other immune cells, astrocytes are CNS-derived and fine-tuned to sense changes in neuronal function. Their ability to sense both neuronal firing and immune responses, and their anatomical tiling within the brain makes astrocytes well-suited to determine the site, size, and character of the immune response.

\section{Astrocytic Regulation of the Innate Immune Response}

One of the functions of reactive astrocytes after CNS injury is to release molecules that attract immune cells specifically to the injured region and facilitate their infiltration from vasculature into the CNS tissue. In models of ischemia, bacterial infection and EAE, astrocytes express leukocyte adhesion molecules, such as intercellular adhesion molecules and vascular cell adhesion molecules [31, 51, 55]. Astrocytic nuclear factor kappa $b$ (NF-kB) signaling has also been demonstrated to increase both intercellular adhesion molecule and vascular cell adhesion molecule expression in tissue [31]. These leukocyte adhesion molecules may stimulate the extravasation of immune cells into the site of injury.

In addition, reactive astrocytes release chemokines, which bind to specific receptors on both peripheral and CNS myeloid cells to attract them to the site of injury. For example, astrocytes are an important source of the peripheral macrophage chemoattractant $\mathrm{C}-\mathrm{C}$ motif chemokine ligand 2 (CCL2; also known as macrophage chemoattractant protein 1) in TBI and parasitic infection $[58,71]$. Astrocytes also produce the microglial chemoattractant chemokine CXC3L1 (C-X3-C motif ligand 1) in response to viral and prion infections, and the neutrophil chemoattractant chemokine CXCL1 (C-X-C motif ligand 1) after spinal cord injury [56, 73, 120].

After entry into the brain (unless already present, as is the case with microglia that are at the injury border) innate immune cells exhibit a complex array of phenotypes, which can be proor anti-inflammatory, and many cells may express cytokines and chemokines consistent with both. This is reviewed in depth elsewhere in this issue by Kim and Cho [121], and recently by Cuartero et al. [122]. More simplistic functional phenotypes can be useful to represent what is happening at set timepoints in an injury or infectious response. Proinflammatory macrophages and activated microglia express high levels of MHC II, present antigens to $\mathrm{T}$ lymphocytes and further activate both adaptive and innate immune responses by releasing proinflammatory cytokines, such as interleukin (IL)-1 $\beta$, interferon (IFN)- $\gamma$ and tumor necrosis factor (TNF)- $\alpha$ [123]. Proinflammatory macrophages can also be neurotoxic, for example, by expressing inducible nitric oxide synthase, which induces the formation of reactive oxygen and nitrogen species and causes free radical damage to surviving tissue [124]. This is also exemplified by data on phagocytosis after stroke, where microglial phagocytosis after neonatal stroke is beneficial [125] but phagocytosis after stroke can also cause bystander injury to neurons [126].

By contrast, anti-inflammatory macrophages are defined by lower MHC II expression, reduced antigen presentation and lower inducible nitric oxide synthase production. Their major function is to dampen inflammatory responses by expressing the anti-inflammatory cytokines IL-4, IL-10, and tumor growth factor (TGF)- $\beta$ [127] (reviewed in [128]). Antiinflammatory macrophage responses may function to limit damage that could otherwise be caused by excessive inflammation. For example, IL-4, IL-10, and TGF- $\beta$ are all neuroprotective in stroke models [129-131].

While it is clear that astrocyte functions after stroke are overall beneficial [30], it is likely that careful coordination of both pro- and anti-inflammatory innate immune responses is required to maximize recovery after stroke. Reactive astrocytes play an essential role in regulating immune responses by releasing cytokines that can stimulate macrophages to adopt either pro- or anti-inflammatory phenotypes. The specific immunoregulatory mechanisms that are likely employed by astrocytes after stroke can be extrapolated from research in other 
models of neuroinflammation. For example, after injury or infection, astrocytes can release cytokines that induce more proinflammatory microglia and macrophages (IFN- $\gamma$, IL-12, and TNF- $\alpha$ ) $[76,77,132]$. However, under similar conditions, astrocytes also have been shown to produce the antiinflammatory cytokines IL-10 and TGF- $\beta$, which could then induce monocytic lineage cells to alter towards less inflammatory phenotypes $[32,55,76]$.

Activated microglia can release chemokines such as CCL2 and CXCL1, as well as the proinflammatory cytokines IL-12 and TNF- $\alpha$, and the anti-inflammatory cytokines IL-10 and TGF- $\beta[133,134]$. Thus, reactive astrocytes could potentially affect the molecular barrier not only by directly producing chemokines and cytokines, but also indirectly, by stimulating the chemokine and cytokine secretion from activated microglia and invading macrophages.

\section{Astrocytic Regulation of the Adaptive Immune Response}

In an analogous role to their functions in the innate immune response, reactive astrocytes are a major source of $\mathrm{T}$ and $\mathrm{B}$ lymphocyte chemoattractants during the adaptive immune response. They express the T lymphocyte chemoattractants CCL5, and CXCL10 in infection models [57, 74, 75]. In addition, human astrocytes express the B lymphocyte chemoattractant B-cell activating factor, as well as the $\mathrm{T}$ lymphocyte chemoattractant CXCL12, in brain samples from patients with multiple sclerosis $[135,136]$.

However, controlling $\mathrm{T}$ lymphocyte migration is not sufficient to regulate the adaptive immune response, because once $\mathrm{T}$ lymphocytes invade the injured tissue, they can differentiate into distinct functional subtypes, which have both beneficial and toxic functions. For example, $\mathrm{CD} 4^{+} / \mathrm{IFN}-\gamma^{+} \mathrm{T}$ helper (Th) 1 lymphocytes are primarily neurotoxic, while $\mathrm{CD}^{+} / \mathrm{FoxP}^{+} \mathrm{T}$ regulatory lymphocytes are neuroprotective (reviewed in [137]).

In models of injury, EAE and infection, reactive astrocytes release cytokines that can induce $\mathrm{T}$ lymphocytes to adopt either pro- or anti-inflammatory phenotypes. Astrocytes that are stimulated by EAE or infectious pathogens in vivo primarily release proinflammatory cytokines, such as IFN- $\gamma$, TNF- $\alpha$, and IL-17, but also anti-inflammatory IL-10 [32, 52, 62, 63, 66]. Meanwhile, in a SCI model reactive astrocytes release anti-inflammatory TGF- $\beta$ [33].

\section{Astrocyte Immunoregulatory Functions are Shaped by the Intracellular Signaling Pathways that are Activated After Injury}

In a similar manner to the astrocyte physical barrier, the molecular barrier to inflammation is controlled by which intracellular signaling pathways are activated in astrocytes (Table 2). Transcriptome analyses of reactive astrocytes after stroke and in a model of bacterial infection revealed that there is a partially overlapping set of activated intracellular signaling pathways and astrocytic components of the molecular, as well as the physical barrier that are upregulated in each condition [55]. Studies on how astrocyte transcriptomes are shaped by proinflammatory stimuli such as lipopolysaccharide and IFN- $\gamma$ in vitro and an anti-inflammatory stimulus, TGF- $\beta$, in vitro and in vivo have further demonstrated how intracellular signaling shapes the pattern of gene expression [138, 139].

The cues that determine whether astrocytes will shape innate and adaptive immune cells to adopt a proinflammatory or an anti-inflammatory phenotype are not completely understood. However, emerging evidence supports a model where astrocytes become pro- or anti-inflammatory based on which of their intracellular signaling pathways get activated.

NF-kB and IL-17 pathways appear to be proinflammatory in reactive astrocytes. Thus, inhibiting astrocytic NF-kB is strongly anti-inflammatory in SCI, ischemia, and EAE [31-33]. Similarly, astrocytic knockout of Act1/IL-17 signaling prevents the IL-17-mediated induction of proinflammatory cytokines in EAE [65].

However, astrocyte signaling that involves either gp130 or estrogen receptor $1 \alpha$ is anti-inflammatory. Astrocytic deficiency of gp130 signaling, which is a receptor for the cytokine IL-6, exacerbates inflammatory cytokine production in EAE and in parasitic infection $[52,53]$. Conditional deletion of estrogen receptor $1 \alpha$ in astrocytes leads to similar outcomes in EAE: it increases both myeloid and lymphoid cell infiltration and reduces survival [64].

Reactive astrocytes can be induced to adopt a proinflammatory phenotype not only by inhibiting an anti-inflammatory signaling pathway, but also by overexpressing proinflammatory cytokines. Thus, increasing astrocytic production of proinflammatory cytokines, including TNF- $\alpha$, IL-12, IL-17, or the T lymphocyte chemoattractant CXCL10, exacerbates T lymphocyte and myeloid cell infiltration into the CNS at baseline and in EAE [67, 140-144]. Similarly, overexpressing astrocytic IL-6 increases immune cell infiltration in SCI and EAE and reduces pathogen burden during viral infection [59-61]. However, overexpressing the typically antiinflammatory cytokine TGF- $\beta$ in astrocytes during EAE also attracts more mononuclear leukocytes [68], possibly owing to its involvement in Th17-mediated autoimmunity [145].

It is difficult to know how much overexpressing cytokines in astrocytes tells us about normal astrocyte function. These studies typically involve a GFAP promoter, which upregulates gene transcription during injury and so to some degree may reflect the physiological increase of each cytokine in reactive astrocytes, but transgenic mouse models may also produce supra-physiologic amounts of any given gene and/or may not replicate physiological time courses. In any case, valuable information may be learned about therapeutic strategies even when the transgenic overexpression of a cytokine is not physiologic. 
A second potential confounding factor in studying how astrocytic cytokines regulate the immune response is that many cytokines can directly target invading pathogens or surviving neurons independently from their effects on immune cells. For example, IL-1 $\beta$ is thought to damage neurons in epilepsy directly [146], while TGF- $\beta$ is neuroprotective in stroke $[131,147]$ and its signaling is required in neurons to promote survival [148]. Similarly, IFN- $\gamma$ and IL-6 have been shown to reduce the parasite burden, as well as activate immune cells during Toxoplasma infection [149, 150]. In this case, since immune cell activation commonly leads to reducing the parasite burden, it can become difficult to determine which effects of astrocytic cytokines control the immune response, and which alter it by affecting the parasite burden directly.

\section{Reactive Astrocytes can Indirectly Regulate Neuroinflammation by Affecting Neuronal Function and Survival}

Astrocytes are physiologically connected to neurons at baseline and retain these connections during injury. Thus, in addition to their immunoregulatory functions, astrocytes can also respond to CNS damage signals by altering neuronal survival and function (Table 3). During injury CNS neurons release a variety of relatively standardized signals; those induced by stroke include excess glutamate, ATP release by injured neurons, and vascular damage.

Dying neurons in stroke, TBI, and during epileptiform activity release glutamate, which is toxic to neurons. However, even at baseline astrocytes are able to counteract glutamate overload by expressing high-affinity glutamate transporters that remove glutamate and protect neurons [151]. In large stroke or other high-stress injuries glutamate uptake by astrocytes is further stimulated by increased extracellular glutamate levels and glucocorticoids $[98,152]$.

Glutamate signaling in astrocytes also instructs them to reduce neuroinflammation by decreasing CCL5, a major T lymphocyte chemoattractant, in vitro [101]. However, inflammation can also impair astrocytic uptake of glutamate, further exacerbating neuronal damage [100], which would, in turn, increase neuroinflammation. For example, when the inflammatory cytokine TNF- $\alpha$ is released by microglia in slice cultures, it signals to astrocytes to release glutamate and amplify excitotoxicity [102].

In summary, astrocyte functions can be viewed as a delicate balance: first, in response to neuronal damage, astrocytes reduce both glutamate excitotoxicity and inflammation, but once the inflammation crosses a certain threshold, it is able to override astrocyte anti-inflammatory functions. This balance is well summarized in a review [98], and appears to be determined by both the type of injury and the cytokines present in the astrocyte environment. It could be speculated that injuries that involve acute changes in glutamate release, such as stroke, TBI, and epilepsy [153], primarily stimulate astrocyte anti-inflammatory functions in response to glutamate. Meanwhile, infections and autoimmune disorders, especially those associated with the release of TNF- $\alpha[154,155]$, tend to have a less acute course and appear to override the "typical" astrocyte response of limiting injury and instead increase inflammation and excitotoxic injury.

In addition to glutamate, neuronal death also induces the release of potassium and ATP from dying cells. Both compounds are able to activate the inflammasome, which is an innate immune mechanism to activate inflammation, via pannexin 1 channels. Pannexin 1 is expressed by astrocytes in mice [156] and humans [107] and connects astrocytic cytoplasm to the extracellular space. In the brain pannexin 1 channels are linked with ATP receptors and can also be opened by potassium [106]. Once activated, astrocytic pannexin 1 channels are able to stimulate the inflammasome, which, in turn, increases the expression of proinflammatory mediators, such as IL-1 $\beta$ and reactive oxygen and nitrogen species [157], TNF- $\alpha$ [108], and the myeloid cell chemoattractant CCL2 (macrophage chemoattractant protein 1) [109]. Finally, ATP also binds to astrocytes and induces them to release glutamate, which contributes to excitoxicity [110].

Astrocytes also affect neuronal health directly by providing metabolic support to neurons by releasing stored glycogen, which is converted to lactate and transported to neurons for energy [158]. Increased glucose uptake and lactate delivery improves neuronal resistance to excitotoxicity [95]. Glucose utilization can also be harmful by increasing the production of reactive oxygen and nitrogen species [96], so is tightly regulated. Both glutamate and the proinflammatory cytokines IFN- $\gamma$, IL-1 $\beta$, IL- 6 , and TNF- $\alpha$ are sufficient to increase glucose utilization in astrocyte cultures, while the antiinflammatory cytokines IL-4 and IL-10 to reduce glucose utilization $[96,159]$.

\section{Interactions Between Signaling Pathways in Astrocytes: Integrating the Signal and Future Research Directions}

Astrocytes receive and emit many signals, and can exert both harmful and helpful effects on the neuroinflammatory response and neural outcomes after injury. As both neurally derived cells with neural functions and also innate immune cells with immune functions, astrocytes truly sit at the nexus of the nervous system and the immune system. One illustration of this is astrocytic production of thrombospondin-1, which has functions in both the CNS and immune systems. At baseline, thrombospondin-1 reduces angiogenesis [160] 
and promotes excitatory synaptogenesis [12]. It is also a strong chemoattractant for monocytes [161], and after stroke, it improves recovery [162].

We are also beginning to understand key intracellular pathways that modify astrocytes. Perhaps unsurprisingly, key immunoregulatory pathways in astrocytes, including NF-kB, STAT3 (signal transducer and activator of transcription 3 ), and TGF- $\beta$ signaling mediators, also serve immunoregulatory functions in other cell types. These intracellular pathways influence multiple astrocyte output functions in response to CNS injury (Tables 1 and 2). Astrocytic NF-kB inhibition in EAE reduces the expression of both ECM components and proinflammatory cytokines [32]. Similarly, astrocytic STAT3 signaling inhibition both impedes scar formation and increases immune cell infiltration after SCI $[34,35]$. In contrast, astrocytic TGF- $\beta$ signaling inhibition selectively affects astrocytic cytokine and chemokine production without altering the physical barrier, and seems to act to localize but not specify the immune response $[69,70]$. In stroke, astrocytic TGF- $\beta$ signaling acts to restrict the number of activated microglia and macrophages, while in toxoplasmic encephalitis it restricts the number of $\mathrm{T}$ lymphocytes. Notably, in both stroke and toxoplasmic encephalitis, astrocytic TGF- $\beta$ signaling is required to control the number of invading immune cells and their physical localization but in neither case does it alter the character of the immune response.

Despite all of the recently accumulated knowledge on astrocytic function, our understanding is poised on the cusp of a truly comprehensive knowledge of the complexity of astrocyte functions in neurological disease, and particularly in stroke. Pro- and anti-inflammatory macrophages have been characterized, respectively, as "M1" and "M2", similar to Th1 and Th2 lymphocytes [133]. However, with macrophages the designation has not been as useful as in lymphocyte biology owing to rapid shifts in cell phenotypes along multidimensional axes under different inflammatory conditions. Similar astrocyte polarization in injury states may also occur [163]. In this paradigm "A1" reactive astrocytes are detrimental and "A2" reactive astrocytes are beneficial. Future studies will determine if this is a useful paradigm; in other words, whether there are a limited number of pathways that determine whether an astrocyte is primarily pro- or anti-inflammatory. Or, conversely, it may be that the small number of intracellular pathways that we now know to influence astrocyte output are actually just the tip of the iceberg. Instead, astrocytes may be such complex integrators of their multitudinous inputs that true understanding will require definition of a much higher number of intracellular pathways, and the ways in which they interact, to truly predict the astrocytic output in different disease contexts.
Newer techniques are now available and beginning to yield more information on astrocyte complexity, making it possible to define the signaling pathway networks in reactive astrocytes. These include sorting of individual astrocytes from adult mouse brain [55] and generating astrocyte-specific translatomes directly from spinal cord tissue [37]. Proteomics analysis, similar to studies on multiple sclerosis markers [164], may also aid in identifying astrocyte subtypes, potential novel markers, and intracellular networks. In combination with techniques such as laser-capture microdissection that can identify transcriptomes in cells based on their location relative to the stroke [165], or injury [37], a key objective for astrocyte biologists will be to discover if there exists a set of the main polarizing pathways that are functionally relevant in disease, and to dissect which immune and CNS injury signals induce reactive astrocyte polarization. If all pathways are similarly important, these new techniques should help us understand the rules that astrocytes utilize to integrate the multidimensional input they receive, and allow us to predict their output.

Aside from understanding the multitude of CNS inputs that astrocytes receive from neurons, glia, pathogens, and responding immune cells, we will need to understand how physical and temporal distance from a neurological lesion influences astrocytic responses. In addition, factors that influence systemic inflammatory state (e.g., age, sex, obesity, hypercholesterolemia, and diabetes) are also likely to influence astrocytic immune functions. For example, gut microbiota can influence astrocytic regulation of immune responses [166]. Astrocytes in patients with multiple sclerosis and EAE mice express aryl hydrocarbon receptors that directly respond to microbial metabolites of tryptophan to reduce inflammation and disease severity in mouse models [166]. Finally, there are important differences between mouse and human astrocytes that will be important to understand in order to translate findings in mouse models to humans with neurological diseases [167].

\section{Conclusion}

The last couple of decades have greatly enhanced our understanding of astrocytes as participants in and regulators of the neuroinflammatory response in neurological diseases, including stroke.

One major reason that astrocytes are a particularly desirable therapeutic target for stroke is because they can sense and directly affect damaged neurons and also simultaneously regulate inflammation. Also, astrocyte activation is physically restricted to the stroke border and present during the days to weeks after stroke, providing a therapeutically useful time window. Understanding how astrocyte functions are regulated by their intracellular pathways beyond the few described 
above will suggest specific therapeutic mechanisms and broaden our understanding of astrocytes as mediators of responses to CNS injury. Eventually, this knowledge could potentially be applied to targeting astrocytes to limit inflammation in other neurological diseases and even to understanding the role of glial cells in immune regulation in organ systems outside the CNS.

Acknowledgments This work was supported by the National Institutes of Health, National Institute of Neurological Disorders and Stroke, R01 NS067132.

Required Author Forms Disclosure forms provided by the authors are available with the online version of this article.

\section{References}

1. Anderson CM, Swanson RA. Astrocyte glutamate transport: review of properties, regulation, and physiological functions. Glia 2000;32:1-14.

2. Barres BA. The mystery and magic of glia: a perspective on their roles in health and disease. Neuron 2008;60:430-440.

3. Sofroniew MV, Vinters HV. Astrocytes: biology and pathology. Acta Neuropathol 2010;119:7-35.

4. Ousman SS, Kubes P. Immune surveillance in the central nervous system. Nat Neurosci 2012;15:1096-1101.

5. Zhang Y, Barres BA. Astrocyte heterogeneity: an underappreciated topic in neurobiology. Curr Opin Neurobiol 2010;20:588-594.

6. Emsley JG, Macklis JD. Astroglial heterogeneity closely reflects the neuronal-defined anatomy of the adult murine CNS. Neuron Glia Biol 2006;2:175-186.

7. Doyle JP, Dougherty JD, Heiman M, et al. Application of a translational profiling approach for the comparative analysis of CNS cell types. Cell 2008;135:749-762.

8. Bailey MS, Shipley MT. Astrocyte subtypes in the rat olfactory bulb: morphological heterogeneity and differential laminar distribution. J Comp Neurol 1993;328:501-526.

9. Hochstim C, Deneen B, Lukaszewicz A, Zhou Q, Anderson DJ. Identification of positionally distinct astrocyte subtypes whose identities are specified by a homeodomain code. Cell 2008;133: 510-522.

10. Muroyama Y, Fujiwara Y, Orkin SH, Rowitch DH. Specification of astrocytes by bHLH protein SCL in a restricted region of the neural tube. Nature 2005;438:360-363.

11. Pascual O, Casper KB, Kubera C, et al. Astrocytic purinergic signaling coordinates synaptic networks. Science 2005;310:113116.

12. Christopherson KS, Ullian EM, Stokes CC, et al. Thrombospondins are astrocyte-secreted proteins that promote CNS synaptogenesis. Cell 2005;120:421-433.

13. Bialas AR, Stevens B. TGF-beta signaling regulates neuronal C1q expression and developmental synaptic refinement. Nat Neurosci 2013; 16:1773-1782.

14. Suzuki A, Stern SA, Bozdagi O, et al. Astrocyte-neuron lactate transport is required for long-term memory formation. Cell 2011;144:810-823.

15. Regan MR, Huang YH, Kim YS, et al. Variations in promoter activity reveal a differential expression and physiology of glutamate transporters by glia in the developing and mature CNS. J Neurosci 2007;27:6607-6619.
16. Giaume C, Koulakoff A, Roux L, Holcman D, Rouach N. Astroglial networks: a step further in neuroglial and gliovascular interactions. Nat Rev Neurosci 2010;11:87-99.

17. Houades V, Koulakoff A, Ezan P, Seif I, Giaume C. Gap junctionmediated astrocytic networks in the mouse barrel cortex. J Neurosci 2008;28:5207-5217.

18. Nagy JI, Rash JE. Connexins and gap junctions of astrocytes and oligodendrocytes in the CNS. Brain Res Brain Res Rev 2000;32: 29-44.

19. Rinholm JE, Hamilton NB, Kessaris N, Richardson WD, Bergersen LH, Attwell D. Regulation of oligodendrocyte development and myelination by glucose and lactate. J Neurosci 2011;31:538-548.

20. Hurwitz AA, Berman JW, Rashbaum WK, Lyman WD. Human fetal astrocytes induce the expression of blood-brain barrier specific proteins by autologous endothelial cells. Brain Res 1993;625: 238-243.

21. Iadecola C, Anrather J. The immunology of stroke: from mechanisms to translation. Nat Med 2011;17:796-808.

22. Bao Y, Qin L, Kim E, et al. CD36 is involved in astrocyte activation and astroglial scar formation. J Cereb Blood Flow Metab 2012;32:1567-1577.

23. Ben Haim L, Carrillo-de Sauvage MA, Ceyzeriat K, Escartin C. Elusive roles for reactive astrocytes in neurodegenerative diseases. Front Cell Neurosci 2015;9:278.

24. Romao LF, Sousa Vde O, Neto VM, Gomes FC. Glutamate activates GFAP gene promoter from cultured astrocytes through TGFbeta1 pathways. J Neurochem 2008;106:746-756.

25. Neary JT, Kang Y, Willoughby KA, Ellis EF. Activation of extracellular signal-regulated kinase by stretch-induced injury in astrocytes involves extracellular ATP and P2 purinergic receptors. J Neurosci 2003;23:2348-2356.

26. Huang XJ, Zhang WP, Li CT, et al. Activation of CysLT receptors induces astrocyte proliferation and death after oxygen-glucose deprivation. Glia 2008;56:27-37.

27. Farina C, Aloisi F, Meinl E. Astrocytes are active players in cerebral innate immunity. Trends Immunol 2007;28:138-145.

28. Wilson EH, Hunter CA. The role of astrocytes in the immunopathogenesis of toxoplasmic encephalitis. Int J Parasitol 2004;34:543-548.

29. Shimada IS, Borders A, Aronshtam A, Spees JL. Proliferating reactive astrocytes are regulated by Notch-1 in the peri-infarct area after stroke. Stroke 2011;42:3231-3237.

30. Li L, Lundkvist A, Andersson D, et al. Protective role of reactive astrocytes in brain ischemia. J Cereb Blood Flow Metab 2008;28: 468-481.

31. Dvoriantchikova G, Barakat D, Brambilla R, et al. Inactivation of astroglial NF-kappa B promotes survival of retinal neurons following ischemic injury. Eur J Neurosci 2009;30:175-185.

32. Brambilla R, Bracchi-Ricard $\mathrm{V}, \mathrm{Hu} \mathrm{WH}$, et al. Inhibition of astroglial nuclear factor kappaB reduces inflammation and improves functional recovery after spinal cord injury. J Exp Med 2005;202:145-156.

33. Brambilla R, Hurtado A, Persaud T, et al. Transgenic inhibition of astroglial NF-kappa B leads to increased axonal sparing and sprouting following spinal cord injury. J Neurochem 2009;110: 765-778.

34. Wanner IB, Anderson MA, Song B, et al. Glial scar borders are formed by newly proliferated, elongated astrocytes that interact to corral inflammatory and fibrotic cells via STAT3-dependent mechanisms after spinal cord injury. J Neurosci 2013;33:12870-12886.

35. Okada S, Nakamura M, Katoh H, et al. Conditional ablation of Stat3 or Socs 3 discloses a dual role for reactive astrocytes after spinal cord injury. Nat Med 2006;12:829-834. 
36. Herrmann JE, Imura T, Song B, et al. STAT3 is a critical regulator of astrogliosis and scar formation after spinal cord injury. $\mathrm{J}$ Neurosci 2008;28:7231-7243.

37. Anderson MA, Burda JE, Ren Y, et al. Astrocyte scar formation aids central nervous system axon regeneration. Nature 2016;532: 195-200.

38. McKillop WM, Dragan M, Schedl A, Brown A. Conditional Sox9 ablation reduces chondroitin sulfate proteoglycan levels and improves motor function following spinal cord injury. Glia 2013;61: 164-177.

39. Hsu JY, Bourguignon LY, Adams CM, et al. Matrix metalloproteinase-9 facilitates glial scar formation in the injured spinal cord. J Neurosci 2008;28:13467-13477.

40. Faulkner JR, Herrmann JE, Woo MJ, Tansey KE, Doan NB, Sofroniew MV. Reactive astrocytes protect tissue and preserve function after spinal cord injury. J Neurosci 2004;24:2143-2155.

41. Schachtrup C, Ryu JK, Helmrick MJ, et al. Fibrinogen triggers astrocyte scar formation by promoting the availability of active TGF-beta after vascular damage. J Neurosci 2010;30:5843-5854.

42. Smith GM, Hale JH. Macrophage/Microglia regulation of astrocytic tenascin: synergistic action of transforming growth factorbeta and basic fibroblast growth factor. J Neurosci 1997;17:96249633.

43. Wang Y, Moges H, Bharucha Y, Symes A. Smad3 null mice display more rapid wound closure and reduced scar formation after a stab wound to the cerebral cortex. Exp Neurol 2007;203:168-184.

44. Bush TG, Puvanachandra N, Horner CH, et al. Leukocyte infiltration, neuronal degeneration, and neurite outgrowth after ablation of scar-forming, reactive astrocytes in adult transgenic mice. Neuron 1999;23:297-308

45. Myer DJ, Gurkoff GG, Lee SM, Hovda DA, Sofroniew MV. Essential protective roles of reactive astrocytes in traumatic brain injury. Brain 2006;129:2761-2772.

46. Herx LM, Yong VW. Interleukin-1 beta is required for the early evolution of reactive astrogliosis following CNS lesion. J Neuropathol Exp Neurol 2001;60:961-971.

47. Bardehle S, Kruger M, Buggenthin F, et al. Live imaging of astrocyte responses to acute injury reveals selective juxtavascular proliferation. Nat Neurosci 2013;16:580-586.

48. Balasingam V, Tejada-Berges T, Wright E, Bouckova R, Yong VW. Reactive astrogliosis in the neonatal mouse brain and its modulation by cytokines. J Neurosci 1994;14:846-856.

49. Gadea A, Schinelli S, Gallo V. Endothelin-1 regulates astrocyte proliferation and reactive gliosis via a JNK/c-Jun signaling pathway. J Neurosci 2008;28:2394-2408.

50. Voskuhl RR, Peterson RS, Song B, et al. Reactive astrocytes form scar-like perivascular barriers to leukocytes during adaptive immune inflammation of the CNS. J Neurosci 2009;29:1151111522.

51. Gimenez MA, Sim JE, Russell JH. TNFR1-dependent VCAM-1 expression by astrocytes exposes the CNS to destructive inflammation. J Neuroimmunol 2004;151:116-125.

52. Haroon F, Drogemuller K, Handel U, et al. Gp130-dependent astrocytic survival is critical for the control of autoimmune central nervous system inflammation. J Immunol 2011;186:6521-6531.

53. Drogemuller K, Helmuth U, Brunn A, et al. Astrocyte gp130 expression is critical for the control of Toxoplasma encephalitis. J Immunol 2008;18:2683-2693.

54. Stenzel W, Soltek S, Schluter D, Deckert M. The intermediate filament GFAP is important for the control of experimental murine Staphylococcus aureus-induced brain abscess and Toxoplasma encephalitis. J Neuropathol Exp Neurol 2004;63:631-640.

55. Zamanian JL, Xu L, Foo LC, et al. Genomic analysis of reactive astrogliosis. J Neurosci 2012;32:6391-6410.

56. Pineau I, Sun L, Bastien D, Lacroix S. Astrocytes initiate inflammation in the injured mouse spinal cord by promoting the entry of neutrophils and inflammatory monocytes in an IL-1 receptor/ MyD88-dependent fashion. Brain Behav Immun 2010;24:540553.

57. Babcock AA, Kuziel WA, Rivest S, Owens T. Chemokine expression by glial cells directs leukocytes to sites of axonal injury in the CNS. J Neurosci 2003;23:7922-7930.

58. Glabinski AR, Balasingam V, Tani M, et al. Chemokine monocyte chemoattractant protein-1 is expressed by astrocytes after mechanical injury to the brain. J Immunol 1996;156:4363-4368.

59. Quintana A, Giralt M, Molinero A, Campbell IL, Penkowa M, Hidalgo J. Analysis of the cerebral transcriptome in mice subjected to traumatic brain injury: importance of IL- 6 . Neuroimmunomodulation 2007;14:139-143.

60. Quintana A, Muller M, Frausto RF, et al. Site-specific production of IL-6 in the central nervous system retargets and enhances the inflammatory response in experimental autoimmune encephalomyelitis. J Immunol 2009;183:2079-2088.

61. Carr DJ, Campbell IL. Transgenic expression of interleukin-6 in the central nervous system confers protection against acute herpes simplex virus type-1 infection. J Neurovirol 1999;5:449-457.

62. Stuve O, Youssef S, Slavin AJ, et al. The role of the MHC class II transactivator in class II expression and antigen presentation by astrocytes and in susceptibility to central nervous system autoimmune disease. J Immunol 2002;169:6720-6732.

63. Hindinger C, Bergmann CC, Hinton DR, et al. IFN-gamma signaling to astrocytes protects from autoimmune mediated neurological disability. PLoS One 2012;7:e42088.

64. Spence RD, Hamby ME, Umeda E, et al. Neuroprotection mediated through estrogen receptor-alpha in astrocytes. Proc Natl Acad Sci U S A 2011;108:8867-8872.

65. Kang Z, Altuntas CZ, Gulen MF, et al. Astrocyte-restricted ablation of interleukin-17-induced Act1-mediated signaling ameliorates autoimmune encephalomyelitis. Immunity 2010;32:414425.

66. Wang X, Haroon F, Karray S, Martina D, Schluter D. Astrocytic Fas ligand expression is required to induce T-cell apoptosis and recovery from experimental autoimmune encephalomyelitis. Eur J Immunol 2013;43:115-124.

67. Pagenstecher A, Lassmann S, Carson MJ, Kincaid CL, Stalder AK, Campbell IL. Astrocyte-targeted expression of IL-12 induces active cellular immune responses in the central nervous system and modulates experimental allergic encephalomyelitis. J Immunol 2000;164:4481-4492.

68. Wyss-Coray T, Borrow P, Brooker MJ, Mucke L. Astroglial overproduction of TGF-beta 1 enhances inflammatory central nervous system disease in transgenic mice. J Neuroimmunol 1997;77:45-50.

69. Cekanaviciute E, Fathali N, Doyle KP, Williams AM, Han J, Buckwalter MS. Astrocytic transforming growth factor-beta signaling reduces subacute neuroinflammation after stroke in mice. Glia 2014;62:1227-1240.

70. Cekanaviciute E, Dietrich HK, Axtell RC, et al. Astrocytic TGFbeta signaling limits inflammation and reduces neuronal damage during central nervous system Toxoplasma infection. J Immunol 2014;193:139-149.

71. Strack A, Asensio VC, Campbell IL, Schluter D, Deckert M. Chemokines are differentially expressed by astrocytes, microglia and inflammatory leukocytes in Toxoplasma encephalitis and critically regulated by interferon-gamma. Acta Neuropathol 2002;103:458-468.

72. Butchi NB, Pourciau S, Du M, Morgan TW, Peterson KE. Analysis of the neuroinflammatory response to TLR7 stimulation in the brain: comparison of multiple TLR7 and/or TLR8 agonists. J Immunol 2008;180:7604-7612.

73. Pereira CF, Middel J, Jansen G, Verhoef J, Nottet HS. Enhanced expression of fractalkine in HIV-1 associated dementia. J Neuroimmunol 2001;115:168-175. 
74. Sauder C, Hallensleben W, Pagenstecher A, et al. Chemokine gene expression in astrocytes of Borna disease virus-infected rats and mice in the absence of inflammation. J Virol 2000;74:9267-9280.

75. Kim BO, Liu Y, Zhou BY, He JJ. Induction of C chemokine XCL1 (lymphotactin/single $\mathrm{C}$ motif-1 alpha/activation-induced, T cellderived and chemokine-related cytokine) expression by HIV-1 Tat protein. J Immunol 2004;172:1888-1895.

76. Sun N, Grzybicki D, Castro RF, Murphy S, Perlman S. Activation of astrocytes in the spinal cord of mice chronically infected with a neurotropic coronavirus. Virology 1995;213:482-493.

77. Park C, Lee $\mathrm{S}$, Cho IH, et al. TLR3-mediated signal induces proinflammatory cytokine and chemokine gene expression in astrocytes: differential signaling mechanisms of TLR3-induced IP-10 and IL-8 gene expression. Glia 2006;53:248-256.

78. Shichita T, Sugiyama Y, Ooboshi H, et al. Pivotal role of cerebral interleukin-17-producing gammadeltaT cells in the delayed phase of ischemic brain injury. Nat Med 2009;15:946-950.

79. Fitch MT, Doller C, Combs CK, Landreth GE, Silver J. Cellular and molecular mechanisms of glial scarring and progressive cavitation: in vivo and in vitro analysis of inflammation-induced secondary injury after CNS trauma. J Neurosci 1999;19:8182-8198.

80. Armien AG, $\mathrm{Hu} \mathrm{S}$, Little MR, et al. Chronic cortical and subcortical pathology with associated neurological deficits ensuing experimental herpes encephalitis. Brain Pathol 2010;20:738-750.

81. Rolls A, Shechter R, London A, et al. Two faces of chondroitin sulfate proteoglycan in spinal cord repair: a role in microglia/ macrophage activation. PLoS Med 2008;5:e171.

82. Pekny M, Johansson CB, Eliasson C, et al. Abnormal reaction to central nervous system injury in mice lacking glial fibrillary acidic protein and vimentin. J Cell Biol 1999;145:503-514.

83. Sun D, Qu J, Jakobs TC. Reversible reactivity by optic nerve astrocytes. Glia 2013;61:1218-1235.

84. Wilhelmsson U, Bushong EA, Price DL, et al. Redefining the concept of reactive astrocytes as cells that remain within their unique domains upon reaction to injury. Proc Natl Acad Sci U S A 2006;103:17513-17518.

85. Haupt C, Witte OW, Frahm C. Up-regulation of Connexin 43 in the glial scar following photothrombotic ischemic injury. Mol Cell Neurosci 2007;35:89-99.

86. Jones LL, Margolis RU, Tuszynski MH. The chondroitin sulfate proteoglycans neurocan, brevican, phosphacan, and versican are differentially regulated following spinal cord injury. Exp Neurol 2003;182:399-411.

87. Davies SJ, Fitch MT, Memberg SP, Hall AK, Raisman G, Silver J. Regeneration of adult axons in white matter tracts of the central nervous system. Nature 1997;390:680-683.

88. McKeon RJ, Jurynec MJ, Buck CR. The chondroitin sulfate proteoglycans neurocan and phosphacan are expressed by reactive astrocytes in the chronic CNS glial scar. J Neurosci 1999;19: 10778-10788.

89. Sikasunge CS, Johansen MV, Phiri IK, Willingham AL, 3rd, Leifsson PS. The immune response in Taenia solium neurocysticercosis in pigs is associated with astrogliosis, axonal degeneration and altered blood-brain barrier permeability. Vet Parasitol 2009;160:242-250.

90. Poluektova L, Gorantla S, Faraci J, Birusingh K, Dou H, Gendelman HE. Neuroregulatory events follow adaptive immune-mediated elimination of HIV-1-infected macrophages: studies in a murine model of viral encephalitis. J Immunol 2004;172:7610-7617.

91. Schittone SA, Dionne KR, Tyler KL, Clarke P. Activation of innate immune responses in the central nervous system during reovirus myelitis. J Virol 2012;86:8107-8118.

92. Monnier PP, Sierra A, Schwab JM, Henke-Fahle S, Mueller BK. The Rho/ROCK pathway mediates neurite growth-inhibitory activity associated with the chondroitin sulfate proteoglycans of the CNS glial scar. Mol Cell Neurosci 2003;22:319-330.

93. Gilbert RJ, McKeon RJ, Darr A, Calabro A, Hascall VC, Bellamkonda RV. CS-4,6 is differentially upregulated in glial scar and is a potent inhibitor of neurite extension. Mol Cell Neurosci 2005;29:545-558.

94. Gates MA, Fillmore H, Steindler DA. Chondroitin sulfate proteoglycan and tenascin in the wounded adult mouse neostriatum in vitro: dopamine neuron attachment and process outgrowth. $\mathrm{J}$ Neurosci 1996;16:8005-8018.

95. Bliss TM, Ip M, Cheng E, et al. Dual-gene, dual-cell type therapy against an excitotoxic insult by bolstering neuroenergetics. J Neurosci 2004;24:6202-6208.

96. Gavillet M, Allaman I, Magistretti PJ. Modulation of astrocytic metabolic phenotype by proinflammatory cytokines. Glia 2008;56:975-989.

97. Kostic M, Zivkovic N, Stojanovic I. Multiple sclerosis and glutamate excitotoxicity. Rev in Neurosci 2013;24:71-88.

98. Tilleux S, Hermans E. Neuroinflammation and regulation of glial glutamate uptake in neurological disorders. J Neurosci Res 2007;85:2059-2070.

99. Agulhon C, Sun MY, Murphy T, Myers T, Lauderdale K, Fiacco TA. Calcium Signaling and gliotransmission in normal vs. reactive astrocytes. Front Pharmacol 2012;3:139.

100. Prow NA, Irani DN. The inflammatory cytokine, interleukin-1 beta, mediates loss of astroglial glutamate transport and drives excitotoxic motor neuron injury in the spinal cord during acute viral encephalomyelitis. J Neurochem 2008;105:1276-1286.

101. Besong G, Battaglia G, D'Onofrio M, et al. Activation of group III metabotropic glutamate receptors inhibits the production of RANTES in glial cell cultures. J Neurosci 2002;22:5403-5411.

102. Bezzi P, Domercq M, Brambilla L, et al. CXCR4-activated astrocyte glutamate release via TNFalpha: amplification by microglia triggers neurotoxicity. Nat Neurosci 2001;4:702-710.

103. Panickar KS, Norenberg MD. Astrocytes in cerebral ischemic injury: morphological and general considerations. Glia 2005;50: 287-298.

104. Ravizza T, Gagliardi B, Noe F, Boer K, Aronica E, Vezzani A. Innate and adaptive immunity during epileptogenesis and spontaneous seizures: evidence from experimental models and human temporal lobe epilepsy. Neurobiol Dis 2008;29:142-160.

105. Crespel A, Coubes P, Rousset MC, et al. Inflammatory reactions in human medial temporal lobe epilepsy with hippocampal sclerosis. Brain Res 2002;952:159-169.

106. Silverman WR, de Rivero Vaccari JP, et al. The pannexin 1 channel activates the inflammasome in neurons and astrocytes. J Biol Chem 2009;284:18143-18151.

107. Minkiewicz J, de Rivero Vaccari JP, Keane RW. Human astrocytes express a novel NLRP2 inflammasome. Glia 2013;61:1113-1121.

108. Xia M, Zhu Y. FOXO3a involvement in the release of TNF-alpha stimulated by ATP in spinal cord astrocytes. J Mol Neurosci 2013;51:792-804.

109. Panenka W, Jijon H, Herx LM, et al. P2X7-like receptor activation in astrocytes increases chemokine monocyte chemoattractant protein-1 expression via mitogen-activated protein kinase. $\mathrm{J}$ Neurosci 2001;21:7135-7142.

110. Pascual O, Ben Achour S, Rostaing P, Triller A, Bessis A. Microglia activation triggers astrocyte-mediated modulation of excitatory neurotransmission. Proc Natl Acad Sci U S A 2012;109:E197-E205.

111. Gelderblom M, Leypoldt F, Steinbach K, et al. Temporal and spatial dynamics of cerebral immune cell accumulation in stroke. Stroke 2009; 40:1849-1857.

112. Lampron A, Elali A, Rivest S. Innate immunity in the CNS: redefining the relationship between the CNS and Its environment. Neuron 2013;78:214-232. 
113. Doyle KP, Quach L, Solé M, et al. B-Lymphocyte mediated delayed cognitive impairment following stroke. J Neurosci 2015;35: 2133-2145.

114. Ransohoff RM, Engelhardt B. The anatomical and cellular basis of immune surveillance in the central nervous system. Nat Rev Immunol 2012;12:623-635.

115. Wraith DC, Nicholson LB. The adaptive immune system in diseases of the central nervous system. J Clin Invest 2012;122:11721179.

116. Romo-Gonzalez T, Chavarria A, Perez HJ. Central nervous system: a modified immune surveillance circuit? Brain Behav Immun 2012;26:823-829.

117. Kawakami N, Bartholomaus I, Pesic M, Mues M. An autoimmunity odyssey: how autoreactive T cells infiltrate into the CNS. Immunol Rev 2012;248:140-155.

118. Clarkson BD, Heninger E, Harris MG, Lee J, Sandor M, Fabry Z. Innate-adaptive crosstalk: how dendritic cells shape immune responses in the CNS. Adv Exp Med Biol 2012;946:309-333.

119. Carpentier PA, Begolka WS, Olson JK, Elhofy A, Karpus WJ, Miller SD. Differential activation of astrocytes by innate and adaptive immune stimuli. Glia 2005;49:360-374.

120. Hughes PM, Botham MS, Frentzel S, Mir A, Perry VH. Expression of fractalkine (CX3CL1) and its receptor, CX3CR1, during acute and chronic inflammation in the rodent CNS. Glia 2002;37:314-327.

121. Kim E, Cho S. Microglia and monocyte-derived macrophages in stroke. Neurotherapeutics 2016 Aug 2 [Epub ahead of print].

122. Cuartero MI, Ballesteros I, Lizasoain I, Moro MA. Complexity of the cell-cell interactions in the innate immune response after cerebral ischemia. Brain Res 2015;1623:53-62.

123. Kigerl KA, Gensel JC, Ankeny DP, Alexander JK, Donnelly DJ, Popovich PG. Identification of two distinct macrophage subsets with divergent effects causing either neurotoxicity or regeneration in the injured mouse spinal cord. J Neurosci 2009;29:1343513444.

124. Brown GC. Nitric oxide and neuronal death. Nitric oxide 2010;23: 153-165.

125. Faustino JV, Wang X, Johnson CE, et al. Microglial cells contribute to endogenous brain defenses after acute neonatal focal stroke. J Neurosci 2011;31:12992-13001.

126. Neher JJ, Emmrich JV, Fricker M, Mander PK, Thery C, Brown GC. Phagocytosis executes delayed neuronal death after focal brain ischemia. Proc Natl Acad Sci U S A 2013;110:E4098E4107.

127. Fadok VA, Bratton DL, Konowal A, Freed PW, Westcott JY, Henson PM. Macrophages that have ingested apoptotic cells in vitro inhibit proinflammatory cytokine production through autocrine/paracrine mechanisms involving TGF-b, PGE2, and PAF. J Clin Invest 1998;101:890-898.

128. Martinez FO, Helming L, Gordon S. Alternative activation of macrophages: an immunologic functional perspective. Annu Rev Immunol 2009:27:451-483.

129. Xiong X, Barreto GE, Xu L, Ouyang YB, Xie X, Giffard RG. Increased brain injury and worsened neurological outcome in interleukin-4 knockout mice after transient focal cerebral ischemia. Stroke 2011;42:2026-2032.

130. Spera PA, Ellison JA, Feuerstein GZ, Barone FC. IL-10 reduces rat brain injury following focal stroke. Neurosci Lett 1998;251: 189-192.

131. Ruocco A, Nicole O, Docagne F, et al. A transforming growth factor-beta antagonist unmasks the neuroprotective role of this endogenous cytokine in excitotoxic and ischemic brain injury. J Cereb Blood Flow Metab 1999;19:1345-1353.

132. Constantinescu CS, Tani M, Ransohoff RM, et al. Astrocytes as antigen-presenting cells: expression of IL-12/IL-23. J Neurochem 2005;95:331-340.
133. Mantovani A, Sica A, Allavena P, Garlanda C, Locati M. Tumorassociated macrophages and the related myeloid-derived suppressor cells as a paradigm of the diversity of macrophage activation. Hum Immunol 2009;70:325-330.

134. Garcia Samartino C, Delpino MV, Pott Godoy C, et al. Brucella abortus induces the secretion of proinflammatory mediators from glial cells leading to astrocyte apoptosis. Am J Pathol 2010;176: 1323-1338.

135. Krumbholz M, Theil D, Cepok S, et al. Chemokines in multiple sclerosis: CXCL12 and CXCL13 up-regulation is differentially linked to CNS immune cell recruitment. Brain 2006;129:200-211.

136. Krumbholz M, Theil D, Derfuss T, et al. BAFF is produced by astrocytes and up-regulated in multiple sclerosis lesions and primary central nervous system lymphoma. J Exp Med 2005;201:195-200.

137. Goverman J. Autoimmune T cell responses in the central nervous system. Nat Rev Immunol 2009;9:393-407.

138. Hamby ME, Coppola G, Ao Y, Geschwind DH, Khakh BS, Sofroniew MV. Inflammatory mediators alter the astrocyte transcriptome and calcium signaling elicited by multiple G-proteincoupled receptors. J Neurosci 2012;32:14489-14510.

139. Cacheaux LP, Ivens S, David Y, et al. Transcriptome profiling reveals TGF-beta signaling involvement in epileptogenesis. J Neurosci 2009;29:8927-8935.

140. Stalder AK, Carson MJ, Pagenstecher A, et al. Late-onset chronic inflammatory encephalopathy in immune-competent and severe combined immune-deficient (SCID) mice with astrocyte-targeted expression of tumor necrosis factor. Am J Pathol 1998;153:767-783.

141. Akassoglou K, Probert L, Kontogeorgos G, Kollias G. Astrocytespecific but not neuron-specific transmembrane TNF triggers inflammation and degeneration in the central nervous system of transgenic mice. J Immunol 1997;158:438-445.

142. Boztug K, Carson MJ, Pham-Mitchell N, Asensio VC, DeMartino J, Campbell IL. Leukocyte infiltration, but not neurodegeneration, in the CNS of transgenic mice with astrocyte production of the CXC chemokine ligand 10. J Immunol 2002;169:1505-1515.

143. Krauthausen M, Ellis SL, Zimmermann J, et al. Opposing roles for CXCR3 signaling in central nervous system versus ocular inflammation mediated by the astrocyte-targeted production of IL-12. Am J Pathol 2011;179:2346-2359.

144. Zimmermann J, Krauthausen M, Hofer MJ, Heneka MT, Campbell IL, Muller M. CNS-targeted production of IL-17A induces glial activation, microvascular pathology and enhances the neuroinflammatory response to systemic endotoxemia. PLoS One 2013;8:e57307.

145. Zepp J, Wu L, Li X. IL-17 receptor signaling and T helper 17mediated autoimmune demyelinating disease. Trends Immunol 2011;32:232-239.

146. Viviani B, Bartesaghi S, Gardoni F, et al. Interleukin-1beta enhances NMDA receptor-mediated intracellular calcium increase through activation of the Src family of kinases. J Neurosci 2003;23:8692-8700.

147. Pang L, Ye W, Che XM, Roessler BJ, Betz AL, Yang GY. Reduction of inflammatory response in the mouse brain with adenoviral-mediated transforming growth factor- 1 expression. Stroke 2001;32:544-552.

148. Tesseur I, Zou K, Esposito L, et al. Deficiency in neuronal TGFbeta signaling promotes neurodegeneration and Alzheimer's pathology. J Clin Invest 2006;116:3060-3069.

149. Suzuki Y, Rani S, Liesenfeld O, et al. Impaired resistance to the development of toxoplasmic encephalitis in interleukin-6deficient mice. Infect Immun 1997;65:2339-2345.

150. Suzuki Y, Sa Q, Gehman M, Ochiai E. Interferon-gammaand perforin-mediated immune responses for resistance against Toxoplasma gondii in the brain. Expert Rev Mol Med 2011;13:e31. 
151. Su ZZ, Leszczyniecka M, Kang DC, et al. Insights into glutamate transport regulation in human astrocytes: cloning of the promoter for excitatory amino acid transporter 2 (EAAT2). Proc Natl Acad Sci U S A 2003;100:1955-1960.

152. Zschocke J, Bayatti N, Clement AM, et al. Differential promotion of glutamate transporter expression and function by glucocorticoids in astrocytes from various brain regions. J Biol Chem 2005;280:34924-34932.

153. Tanaka K, Watase K, Manabe T, et al. Epilepsy and exacerbation of brain injury in mice lacking the glutamate transporter GLT-1. Science 1997;276:1699-1702.

154. Korn T, Magnus T, Jung S. Autoantigen specific T cells inhibit glutamate uptake in astrocytes by decreasing expression of astrocytic glutamate transporter GLAST: a mechanism mediated by tumor necrosis factor-alpha. FASEB J 2005;19:1878-1880.

155. Szymocha R, Akaoka H, Dutuit M, et al. Human T-cell lymphotropic virus type 1-infected $\mathrm{T}$ lymphocytes impair catabolism and uptake of glutamate by astrocytes via Tax-1 and tumor necrosis factor alpha. J Virol 2000;74:6433-6441.

156. Kido $\mathrm{Y}$, Kawahara C, Terai $\mathrm{Y}$, et al. Regulation of activity of $\mathrm{P} 2 \mathrm{X} 7$ receptor by its splice variants in cultured mouse astrocytes. Glia 2014;62:440-451.

157. Pelegrin P, Surprenant A. Pannexin-1 mediates large pore formation and interleukin-1beta release by the ATP-gated P2X7 receptor. EMBO J 2006;25:5071-5082.

158. Pellerin L, Pellegri G, Bittar PG, et al. Evidence supporting the existence of an activity-dependent astrocyte-neuron lactate shuttle. Develop Neurosci 1998;20:291-299.
159. Belanger M, Allaman I, Magistretti PJ. Brain energy metabolism: focus on astrocyte-neuron metabolic cooperation. Cell Metab 2011;14:724-738.

160. Lawler J. Thrombospondin-1 as an endogenous inhibitor of angiogenesis and tumor growth. J Cell Mol Med 2002;6:1-12.

161. Mansfield PJ, Suchard SJ. Thrombospondin promotes chemotaxis and haptotaxis of human peripheral blood monocytes. J Immunol 1994;153(9):4219-4229.

162. Liauw J, Hoang S, Choi M, et al. Thrombospondins 1 and 2 are necessary for synaptic plasticity and functional recovery after stroke. J Cereb Blood Flow Metab 2008;28(10):1722-1732.

163. Liddelow S, Barres B. SnapShot: Astrocytes in health and disease. Cell 2015;162:1170- e1.

164. Han MH, Hwang SI, Roy DB, et al. Proteomic analysis of active multiple sclerosis lesions reveals therapeutic targets. Nature 2008;451:1076-1081.

165. Overman JJ, Clarkson AN, Wanner IB, et al. A role for ephrin-A5 in axonal sprouting, recovery, and activity-dependent plasticity after stroke. Proc Natl Acad Sci U S A 2012;109:E2230-E2229.

166. Rothhammer V, Mascanfroni ID, Bunse L, et al. Type I interferons and microbial metabolites of tryptophan modulate astrocyte activity and central nervous system inflammation via the aryl hydrocarbon receptor. Nat Med 2016;22:586-597.

167. Zhang Y, Sloan SA, Clarke LE, et al. Purification and characterization of progenitor and mature human astrocytes reveals transcriptional and functional differences with mouse. Neuron 2016;89:37-53. 